\title{
Análise dos perigos aos movimentos de massa e enxurradas na Vila Medianeira - Faxinal Do Soturno - RS
}

\author{
Analysis of the hazards to mass movements and flash floods in Vila \\ Medianeira - Faxinal Do Soturno - RS
}

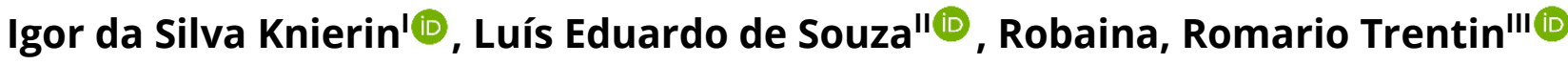 \\ ' Universidade Federal de Santa Maria, Santa Maria, RS, Brasil \\ "Universidade Federal de Santa Maria, Santa Maria, RS, Brasil \\ III Universidade Federal de Santa Maria, Santa Maria, RS, Brasil
}

\section{RESUMO}

Os processos naturais desencadeados por movimentos de massa e enxurradas podem ocasionar danos quando atingem uma comunidade no espaço urbano das cidades. Esta problemática é recorrente na vila Medianeira, localizada na área urbana de Faxinal do Soturno - Rio Grande do Sul - Brasil. O artigo foi desenvolvido a partir da seleção de variáveis para analisar o perigo de processos que ocasionam danos (movimentos de massa e enxurradas) e foram organizadas em uma ficha cadastral que agregou pesos e notas, estruturada em quatro graus para o perigo: baixo, médio, alto e muito alto. Como resultados, foram analisadas 70 edificações, segmentadas, respectivamente em $27,15 \%$ com perigo baixo, $25,71 \%$ com perigo médio, $25,71 \%$ com perigo alto e $21,43 \%$ com perigo muito alto. O estudo contribui para gestão e gerenciamento de risco de desastres naturais na área de estudo, para a mitigação das situações de perigo e como base para estudos em outras áreas suscetíveis a danos no município.

Palavras-chave: Enxurrada; Movimento de massa; Perigo

\section{ABSTRACT}

The natural processes of mass movements and flash floods can cause damage when they reach a community in the urban space of cities. This problem is recurrent in vila Medianeira, is located in the urban area of Faxinal do Soturno, central region of Rio Grande do Sul, Brazil. The article was developed from the selection of variables based on literature review to measure the hazard of processes that cause damage (mass movement and flash flood) and enable the elaboration of a model cadastral of hazard that added values and notes, and four degrees of severity were structured for the hazard: low, medium, high and very high. As results, were registered 70 buildings in vila Medianeira, of these $27.15 \%$ presented in low hazard condition, $25.71 \%$ medium hazard, $25.71 \%$ high hazard and $21.43 \%$ of very high hazard. In 
this sense, the study can be used in the management of the risk of natural disasters in the municipality of Faxinal do Soturno, for more effective actions to mitigate hazardous situations and may also be adopted as a basis for studies in other areas susceptible to damage in the municipality.

Keywords: Flash flood; Mass movement; Hazard

\section{INTRODUÇÃO}

A Geografia é uma ciência possibilita o estudo das relações entre o ser humano e a natureza. Portanto, representa uma área do conhecimento com as condições necessárias para se abordar o tema desastres naturais, que conceitualmente representam as consequências de um fenômeno natural que afeta uma comunidade ou sociedade, ocasionando-Ihes danos e consequências que excedem sua capacidade para se reestabelecer e conviver com os impactos (UNISDR, 2009; NUNES, 2015; TOMINAGA, 2015b).

No tocante dessa temática, ampliaram-se as pesquisas voltadas para o conhecimento e previsão dos desastres naturais, em razão das perdas sociais e materiais resultantes de eventos catastróficos (MAIA, 2002; TOMINAGA, 2015b). Segundo Nogueira (2006), áreas suscetíveis a ocorrência de eventos naturais, como os movimentos de massa e as enxurradas, oferecem um perigo quando ocupadas. Nesse sentido, o estudo de áreas suscetíveis a desastres naturais apresenta como finalidade a identificação dos locais que, em razão de fatores e condicionantes naturais e/ou induzidos, estão associados a ocorrência de processos de dinâmica natural que podem ocasionar danos.

Guidicini e Nieble (1984) adotam a terminologia "agentes predisponentes", o que corresponde ao conjunto de condições geológicas, topográficas e ambientais da área onde se desenvolve o processo que ocasiona dano. Os autores também fazem referência aos "agentes efetivos", que se caracterizam pelo conjunto de fatores diretamente responsáveis pelo desencadeamento dos processos, dentre os quais está incluso a ação antrópica. 
Integrado ao tema dos desastres naturais, destaca-se o conceito de perigo (do inglês hazard), que corresponde a um fenômeno perigoso, que pode causar perda de vidas, ferimentos ou outros impactos à saúde, danos à propriedade, perda de meios de subsistência e serviços, interrupção social e econômica ou danos ambientais (UNISDR, 2009). No Glossário de Defesa Civil (CASTRO, 1998) o perigo é observado com equivalência a ameaça e é definido como uma condição potencial ou real que pode vir a causar morte, ferimento ou dano à propriedade.

A partir da identificação das áreas de perigo é possível estabelecer os locais sujeitos a processos que podem ser mais ou menos severos e impactantes em função dos elementos condicionantes (MENEZES, 2014). Nesse sentido, o mapa de perigo representa a probabilidade espacial e temporal de ocorrer um processo ou um fenômeno com potencial de causar danos e os métodos para sua análise são diversificados, uma vez que são condicionados ao tipo de processo e as características da área de estudo (TOMINAGA, 2015a).

Nesse contexto, diferentes autores apresentam a relevância de alguns elementos na análise do perigo, como: sinais de movimentação da encosta, uso e cobertura da terra, distância da edificação ao local de perigo, lançamento/descarte de lixo/entulho, presença de feições erosivas e/ou indício de processo de erosão, concentração de água pluvial em superfície, sistema de drenagem superficial deficiente, lançamento de água servida e/ou vazamento de água/esgoto das tubulações, presença de blocos de rocha, declividade da encosta ou talude, presença de descontinuidades, perfil e plano de curvatura da encosta, área desmatada, presença de vegetação de grande porte isolada e cultivo de espécies exóticas (AUGUSTO FILHO e VIRGILI, 1998; BRASIL, 2007; CERRI et al., 2007; NUMMER e PINHEIRO, 2013; TOMINAGA, 2015c; RODRIGUES e LISTO, 2016).

Na presente pesquisa, entende-se a definição de perigo, ameaça ou hazard, como a possibilidade de (re)ocorrência de um evento adverso com potencial de causar danos sejam de ordem social, econômica, material, entre outros, a uma população. Com base nisso, este artigo apresenta como objetivo analisar o perigo 
de processos que ocasionam danos (movimentos de massa e enxurradas) na vila Medianeira, no município de Faxinal do Soturno - Rio Grande do Sul - Brasil.

\section{METODOLOGIA}

A pesquisa foi desenvolvida a partir da organização de uma de ficha de cadastro para mensurar o perigo de processos que ocasionam danos (movimentos de massa e enxurradas) na área de estudo. Os mapas temáticos foram elaborados no $\operatorname{ArcGIS}^{\circledR} 10.1$ desenvolvido pela ESRI (Environmental Systems Research Institute). Para isso, foi estruturação de um banco de dados georreferenciado e realizado o cadastro pontual das edificações a partir de imagens de satélite ópticas disponíveis no $\operatorname{ArcGIS}^{\circledR} 10.1$, no serviço Basemap - World Imagery, que possuem como fonte a DigitalGlobe, WorldView-2 Satellite Images, datadas de 29 de julho de 2017, com resolução espacial de 50-60 cm.

Nos meses de julho de 2016 e dezembro de 2017 foram realizados trabalhos de campo na área de estudo e tiveram como objetivos o (re)conhecimento do local e das diferentes características físicas das áreas suscetíveis e de perigo a processos que ocasionam danos e validação dos mapeamentos e cadastros realizados. Os trabalhos de campo tiveram suporte logístico da Defesa Civil municipal e foram realizados registros fotográficos, coleta de pontos de controle com uso do GPS Garmin Etrex, descrição de condições que potencializavam a suscetibilidade e perigo a movimentos de massa e enxurradas.

O mapa de localização e dos processos superficiais que ocasionam danos foi elaborado no $\operatorname{ArcGIS}^{\circledR} 10.1$ e possuiu como dados primários a Base Cartográfica do IBGE (2010) na escala 1:50.000 e curvas de nível com equidistância de 10 m extraídas a partir de uma cena de imagem de RADAR SRTM com resolução espacial de $1 \operatorname{arcsec}(30 \mathrm{~m})$. As cicatrizes de movimentos de massa e a área suscetível a enxurradas foram identificadas e delimitadas por meio da análise in loco, com base 
nos trabalhos de campo realizados na área de estudo, consulta a Defesa Civil municipal e entrevista não estruturada com a população que reside no local.

O cadastro de perigo correspondeu ao número de 70 edificações na área de estudo e foi realizado com base na revisão da literatura de diferentes autores (AUGUSTO FILHO e VIRGILI, 1998; ALHEIROS, 1998; CERRI e AMARAL, 1998; BANDEIRA, 2003; BIGARELLA, 2003; TOMINAGA, 2007; 2015c; BRASIL, 2007; CERRI et al., 2007; GUIMARÃES et al., 2008; FARIA, 2011; FERNANDES e AMARAL, 2012; LISTO e VIEIRA, 2012; NUMMER e PINHEIRO, 2013; WIGGERS, 2013; AMARAL e FEIJÓ, 2014; HENRIQUE, 2014; KORMANN, 2014; PAMPLONA e VALENTE, 2014; AVILA, 2015; RODRIGUES e LISTO, 2016) de forma que contemplasse o estado da arte a respeito do tema processos potencializadores de danos e subsidiaram a organização da ficha de cadastro de perigo para movimentos de massa e enxurradas na área de estudo em que foram atribuídos pesos e notas, de acordo com o Quadro 1.

Para o cálculo do perigo individualizou-se a ficha de cadastro em quatro itens que apresentam seus respectivos pesos $(P)$ de influência no desencadeamento de processos que ocasionam danos: indícios de processos que ocasionam danos (peso 35\%), presença de água (peso 30\%), litologia e relevo (peso 20\%) e vegetação (peso 15\%). Em cada item foram contabilizados um número $\mathrm{N}$ de questões, as quais, apresentam a partir do seu somatório total a nota 10.

Quadro 1- Ficha de cadastro de perigo para processos que ocasionam danos para vila Medianeira. 
6 | Análise dos perigos aos movimentos de massa e enxurradas na Vila Medianeira - Faxinal Do Soturno - RS

\begin{tabular}{|c|c|}
\hline \multicolumn{2}{|c|}{ Ficha de cadastro de perigo para processos que ocasionam danos } \\
\hline \multicolumn{2}{|c|}{ Dados gerais: } \\
\hline Equipe: & Número de cadastro: \\
\hline Data: & Coordenadas UTM \\
\hline Local: & Lat.: \\
\hline Rua: & Número de fotografias: \\
\hline \multicolumn{2}{|c|}{ Indicadores de perigo: } \\
\hline \multicolumn{2}{|c|}{ Indícios de processos que ocasionam danos (peso 35\%) } \\
\hline \multicolumn{2}{|c|}{ Sinais de movimentação da encosta (Nota 5,5): 0 - ( ) Não / 5,5 - ( ) Sim } \\
\hline \multicolumn{2}{|c|}{$\begin{array}{l}\text { Distância da edificação ao perigo (Nota 2): } 0 \text { - ( ) } \geq \text { que a amplitude da encosta / } 2 \text { - ( ) < que a amplitude da } \\
\text { encosta }\end{array}$} \\
\hline \multicolumn{2}{|c|}{ Lançamento/descarte de lixo/entulho (Nota 1): 0 - ( ) Não / 1 - ( ) Sim } \\
\hline \multicolumn{2}{|c|}{ Feição erosiva e/ou indício de processo de erosão na base da edificação (Nota 1): 0 - ( ) Não / 1 - ( ) Sim } \\
\hline \multicolumn{2}{|c|}{ Uso e cobertura da terra no quintal (Nota 0,5): 0 - ( ) Impermeável / 0,5 - ( ) Permeável } \\
\hline \multicolumn{2}{|c|}{ Presença de água (peso 30\%) } \\
\hline \multicolumn{2}{|c|}{$\begin{array}{l}\text { Concentração de água pluvial em superfície (inundação brusca ou enxurrada) (Nota 4): } 0 \text { - ( ) Não / } 4 \text { - ( ) } \\
\text { Sim }\end{array}$} \\
\hline \multicolumn{2}{|c|}{ Sistema de drenagem superficial (Nota 3): 0 - ( ) Satisfatório / 1 - ( ) Precário / 2 - ( ) Inexistente } \\
\hline \multicolumn{2}{|c|}{ Lançamento de água servida em superfície (Nota 2): 0 - ( ) Não / 2 - ( ) Sim } \\
\hline \multicolumn{2}{|c|}{ Vazamento de água/esgoto das tubulações (Nota 1): 0 - ( ) Não / 1 - ( ) Sim } \\
\hline \multicolumn{2}{|c|}{ Litologia e relevo (peso 20\%) } \\
\hline \multicolumn{2}{|c|}{ Talude (Nota 3): 0 - ( ) Natural / 3 - ( ) Com corte e aterro } \\
\hline \multicolumn{2}{|c|}{ Presença de blocos de rocha (Nota 3): 0 - ( ) Não / 3 - ( ) Sim } \\
\hline \multicolumn{2}{|c|}{ Declividade da encosta ou talude (Nota 2): 0 - ( ) Leve a plana / 0,5 - ( ) Moderada / 1,5 - ( ) Acentuada } \\
\hline \multicolumn{2}{|c|}{ Presença de descontinuidades (Nota 1): 0 - ( ) Não / 1 - ( ) Sim } \\
\hline \multicolumn{2}{|c|}{ Encosta convergente que potencialize processos de dinâmica fluvial (Nota 1): 0 - ( ) Não / 1 - ( ) Sim } \\
\hline \multicolumn{2}{|c|}{ Vegetação (peso 15\%) } \\
\hline \multicolumn{2}{|c|}{ Vegetação de grande porte isolada (Nota 4): 0 - ( ) Não / 4 - ( ) Sim } \\
\hline \multicolumn{2}{|c|}{ Área desmatada (Nota 3): 0 - ( ) Não / 3 - ( ) Sim } \\
\hline \multicolumn{2}{|c|}{ Área de cultivo de espécies (ex: bananeira) (Nota 3): 0 - ( ) Não / 3 - ( ) Sim } \\
\hline \multicolumn{2}{|c|}{ Processos que ocasionam danos: } \\
\hline Qual/qu & regam \\
\hline
\end{tabular}




\begin{tabular}{|l|l|l|}
\hline \multicolumn{3}{|c|}{ Ficha de cadastro de perigo para processos que ocasionam danos } \\
\hline \multicolumn{2}{|c|}{ Dados gerais: } \\
\hline Equipe: & \multicolumn{1}{|c|}{ Número de cadastro: } \\
\hline Data: & \multicolumn{1}{|c|}{ Lat.: } & Long.: \\
\hline Local: & Número de fotografias: \\
\hline Rua: & Indicadores de perigo: \\
\hline & \\
\hline $\begin{array}{l}\text { ( ) Escorregamento rotacional / ( ) Queda de blocos / ( ) Tombamento de blocos / ( ) Rolamento de blocos } \\
\text { ( ) Corrida de lama / ( ) Corrida de terra /( ) Corrida de detritos / ( ) Inundação brusca ou enxurrada }\end{array}$ \\
\hline \multicolumn{1}{|c|}{ Grau de perigo: } \\
\hline
\end{tabular}

Fonte: Organização dos autores.

Dessa forma, para se estipular o valor de perigo são somadas todas as notas de cada item, multiplicadas pelo seu peso e dividido pelo denominador 10 , sendo assim identificado um valor $\mathrm{X}_{1,2,3,4}$ para cada $\mathrm{um}$.

$$
\frac{(\mathrm{N}+\mathrm{N} \ldots) * \mathrm{P}}{10}=\mathrm{X}_{1,2,3,4} \quad \text { Equação } 1
$$

Onde $\mathrm{N}$ é a nota de cada questão dos itens (a soma das notas de cada item é 10), P é o peso do item (ex.: litologia e relevo - peso 20\%) e X1,2,3,4 é o item (ex.: litologia e relevo).

Sequencialmente são somados os valores $\left(X_{1,2,3,4}\right)$ dos quatro itens (indícios de processos que ocasionam danos, presença de água, litologia e relevo, e vegetação), e assim obtendo-se o valor final do perigo para a edificação.

$$
\mathrm{X}_{1}+\mathrm{X}_{2}+\mathrm{X}_{3}+\mathrm{X}_{4}=\text { Perigo } \quad \text { Equação } 2
$$

Onde $X_{1,2,3,4}$ são os itens (ex.: litologia e relevo).

Para se definir os referidos graus de perigo convencionou-se os valores $\leq 20$ para perigo baixo, > 20 a $\leq 40$ para perigo médio, $>40$ a $\leq 60$ para perigo alto e $>$ 60 para perigo muito alto, conforme apresentados no Quadro 2. A definição destes 
intervalos foi baseada a partir das da modelagem dos dados cadastrais e observações in loco durante os trabalhos de campo, de forma que correspondem as diferentes situações de perigo na área de estudo.

Quadro 2- Graus de perigo de processos que ocasionam danos.

\begin{tabular}{|c|c|}
\hline \multicolumn{2}{|r|}{ Perigo } \\
\hline Grau de perigo & Descrição: \\
\hline $\begin{array}{l}\text { Perigo baixo } \\
\qquad(\leq 20)\end{array}$ & $\begin{array}{l}\text { - Os condicionantes naturais predisponentes e o nível de intervenção antrópica são de } \\
\text { potencialidade baixa para o desenvolvimento de processos que ocasionam danos. } \\
\text { - Poucos indícios de desenvolvimento de processos de instabilização de encostas ou de } \\
\text { enxurradas. }\end{array}$ \\
\hline $\begin{array}{l}\text { Perigo médio } \\
\text { (> } 20 \text { a } \leq 40 \text { ) }\end{array}$ & $\begin{array}{l}\text { - Os condicionantes naturais predisponentes e o nível de intervenção antrópica são de } \\
\text { potencialidade média para o desenvolvimento de processos que ocasionam danos. } \\
\text { - Observa-se a presença de indícios de instabilidade de encostas e/ou de (re)ocorrência } \\
\text { de enxurradas, entretanto incipiente(s). } \\
\text { - Processo de instabilização em estágio inicial de desenvolvimento. }\end{array}$ \\
\hline $\begin{array}{l}\text { Perigo alto } \\
(>40 \mathrm{a} \leq 60)\end{array}$ & $\begin{array}{l}\text { - Os condicionantes naturais e o nível de intervenção antrópica são de potencialidade } \\
\text { alta para o desenvolvimento de processos que ocasionam danos. } \\
\text { - Observa-se a presença significativa de indícios de instabilidade de encostas (trincas no } \\
\text { solo, árvores inclinadas e/ou isoladas, entre outros) e/ou de (re)ocorrência de } \\
\text { enxurradas. } \\
\text { - Processo de instabilização em pleno desenvolvimento, no entanto, sendo ainda } \\
\text { possível monitorar sua evolução e/ou com reincidência de enxurradas. }\end{array}$ \\
\hline $\begin{array}{l}\text { Perigo muito alto } \\
\qquad(>60)\end{array}$ & $\begin{array}{l}\text { - Os condicionantes naturais predisponentes e o nível de intervenção antrópica são de } \\
\text { potencialidade muito alta para o desenvolvimento de processos que ocasionam danos. } \\
\text { - Os indícios de instabilidade de encostas (trincas no solo, trincas em moradias ou em } \\
\text { muros, árvores inclinadas e/ou isoladas, cicatrizes de escorregamentos, feições } \\
\text { erosivas, presença de blocos, entre outros) são expressivos e estão presentes em } \\
\text { grande número, ou ainda existe a (re)ocorrência de enxurradas. } \\
\text { - Processo de instabilização em avançado estágio de desenvolvimento e/ou } \\
\text { reincidência constante de enxurradas. }\end{array}$ \\
\hline
\end{tabular}

Fonte: Organização dos autores.

\section{RESULTADOS}


A área de estudo se localiza ao norte da área urbana do município de Faxinal do Soturno, na região central do estado do Rio Grande do Sul, no sul do Brasil, com distância aproximada de 269,4 km de Porto Alegre, de acordo com a Figura 1. Na vila Medianeira a ocupação urbana se estabeleceu na base de uma encosta declivosa (morro) e junto a um curso fluvial de primeira ordem, tributário do rio Soturno. No local são comuns situações de perigo de processos que ocasionam danos, como movimentos de massa ou de enxurradas (Figura 1). Estes processos, manifestam-se em função da suscetibilidade natural e induzida, na qual os agentes predisponentes e efetivos contribuem para a gênese de uma área de risco de desastres naturais.

Figura 1- Mapa de localização da vila Medianeira na área urbana de Faxinal do Soturno - RS com a área suscetível a enxurradas e as cicatrizes de movimentos de massa.

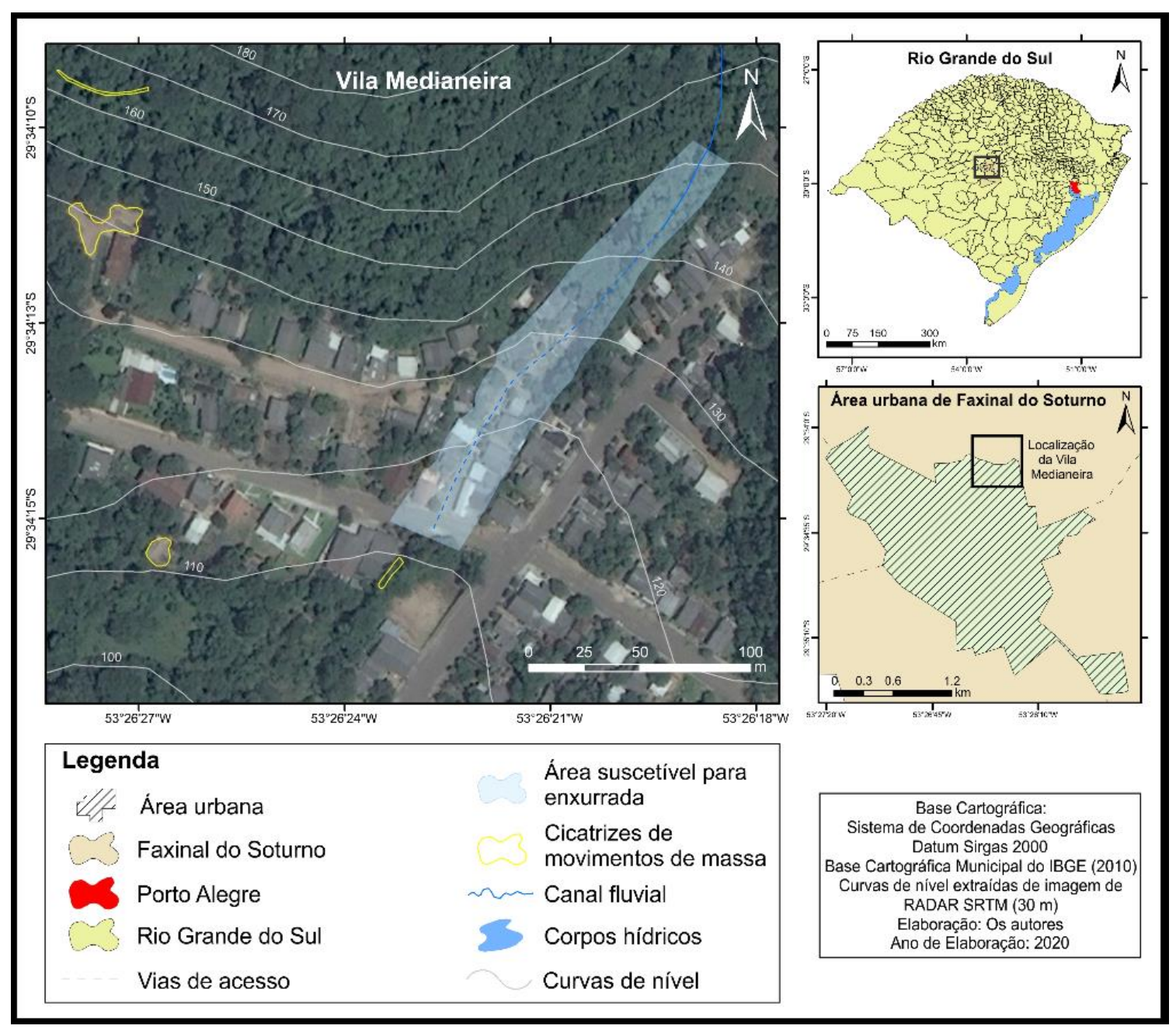

Geog Ens Pesq, Santa Maria, v.26, e10, 2021 
Fonte: Organização dos autores.

Nesse sentido, observam-se ações como a retirada da cobertura vegetal, lançamento de águas servidas, descarte de lixo em locais inadequados, realização de cortes e aterros, cultivo de espécies vegetais que atribuem peso aos taludes, entre outros. Associado a isso, foi registrado na área de estudo a ocorrência de processos de movimentos de massa e de enxurradas de maneira localizada, com base nos registros de decretos de situação de emergência da Defesa Civil (2009, 2010, 2013, 2015 e 2017) e análises in loco.

Os movimentos de massa apresentam sua ocorrência relacionada as intervenções antrópicas localizadas como ações de cortes e aterros, lançamento de águas servidas e descarte de lixo ou dejetos em locais inadequados, desencadeando processos de escorregamento. As enxurradas, por sua vez, ocorrem mediante eventos de precipitação intensa e/ou concentrada, porque a área de estudo localiza-se junto a um curso fluvial de primeira ordem afluente do rio Soturno que foi canalizado no processo de expansão da área urbanizada, o que torna a área suscetível a processos dessa natureza.

A litologia é constituída predominantemente por depósitos de tálus e colúvio de rocha vulcânica da Formação Serra Geral, que cobrem a estrutura da encosta de formações sedimentares de origem fluvial, pertencentes a Formação Caturrita (CPRM, 2006; SCHIRMER, 2012). A encosta possui declividade superior a 30\%, amplitude altimétrica superior a $100 \mathrm{~m}$, o que possibilita a definir como um morro (INSTITUTO DE PESQUISAS TECNOLÓGICAS, 1981). Em relação a sua curvatura apresenta forma convexa no topo e segmentos côncavo-convergentes na base, características que potencializam processos de dinâmica natural, especialmente para movimentos de massa e enxurradas (Figura 2).

Figura 2- Perfil topográfico A-B, localizado na vila Medianeira. 


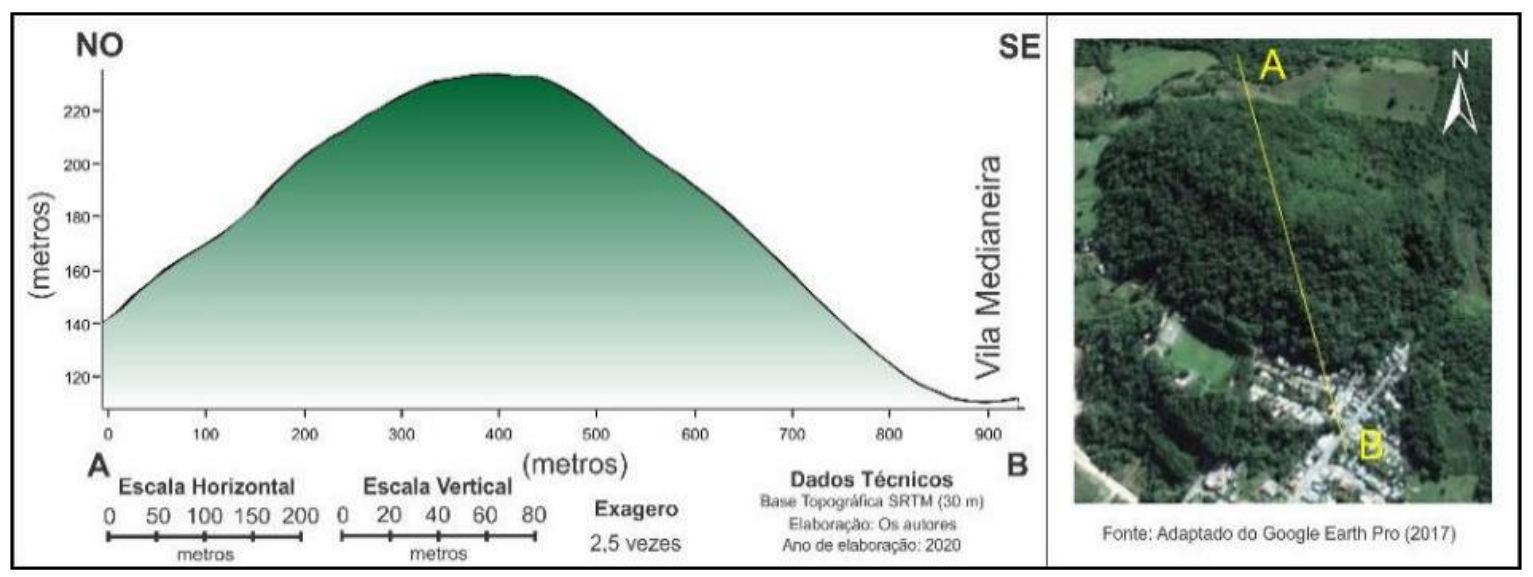

Fonte: Organização dos autores.

\section{Análise do Perigo}

O estudo do perigo retrata as situações de ameaça reproduzidas na área de estudo, segmentado em quatro graus de potencialidade para ocorrência dos processos que ocasionam danos, espacializados de acordo com o mapa da Figura 3.

Figura 3- Mapa de perigo de processos que ocasionam danos, com área suscetível a enxurradas e cicatrizes de movimentos de massa na vila Medianeira. 
12 | Análise dos perigos aos movimentos de massa e enxurradas na Vila Medianeira - Faxinal Do Soturno - RS

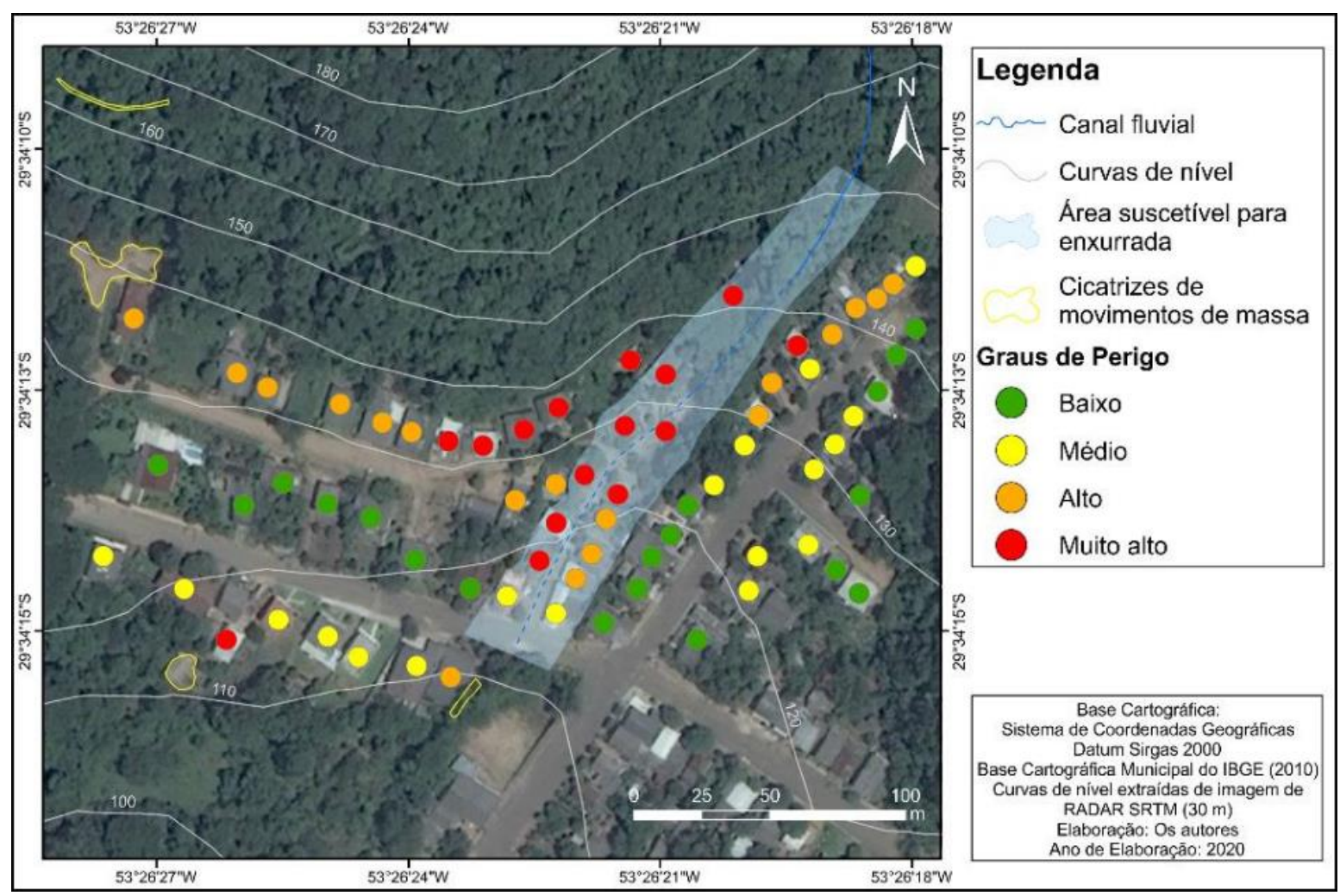

Fonte: Organização dos autores.

No cadastro contabilizou-se um total de 70 edificações, destas 19 encontrase em condição de perigo baixo, 18 em perigo médio, 18 em perigo alto e 15 em perigo muito alto. Na Tabela 1, pode ser observado a distribuição das edificações por graus de perigo segundo seu número total e nos respectivos valores percentuais.

Tabela 1- Quantificação do cadastro de perigo na vila Medianeira.

\begin{tabular}{c|c|c}
\hline Graus de perigo & Número de edificações & Percentual de edificações \\
\hline Perigo baixo & 19 & $27,15 \%$ \\
\hline Perigo médio & 18 & $25,71 \%$ \\
\hline Perigo alto & 18 & $25,71 \%$ \\
\hline Perigo muito alto & 15 & $21,43 \%$ \\
\hline
\end{tabular}

Fonte: Organização dos autores.

As áreas de perigo baixo somam 27,15\% edificações cadastradas (Figura 4), caracterizam-se por apresentar os condicionantes naturais predisponentes e o 
nível de intervenção antrópica de potencialidade baixa para o desenvolvimento de processos que ocasionam danos. Sendo assim, não foram constatados indícios significativos de instabilidade de encosta nem de ocorrência de enxurradas nesses locais.

Dessa forma, configura-se nas áreas de maior segurança diante da ocorrência de desastres naturais no recorte espacial em estudo. A concentração espacial das edificações em situação de perigo baixo está disposta na meia encosta, locais onde a declividade é mais amena, com menor necessidade de intervenções na forma de cortes ou aterros.

Figura 4- Situações de perigo baixo na vila Medianeira (A, B e C).

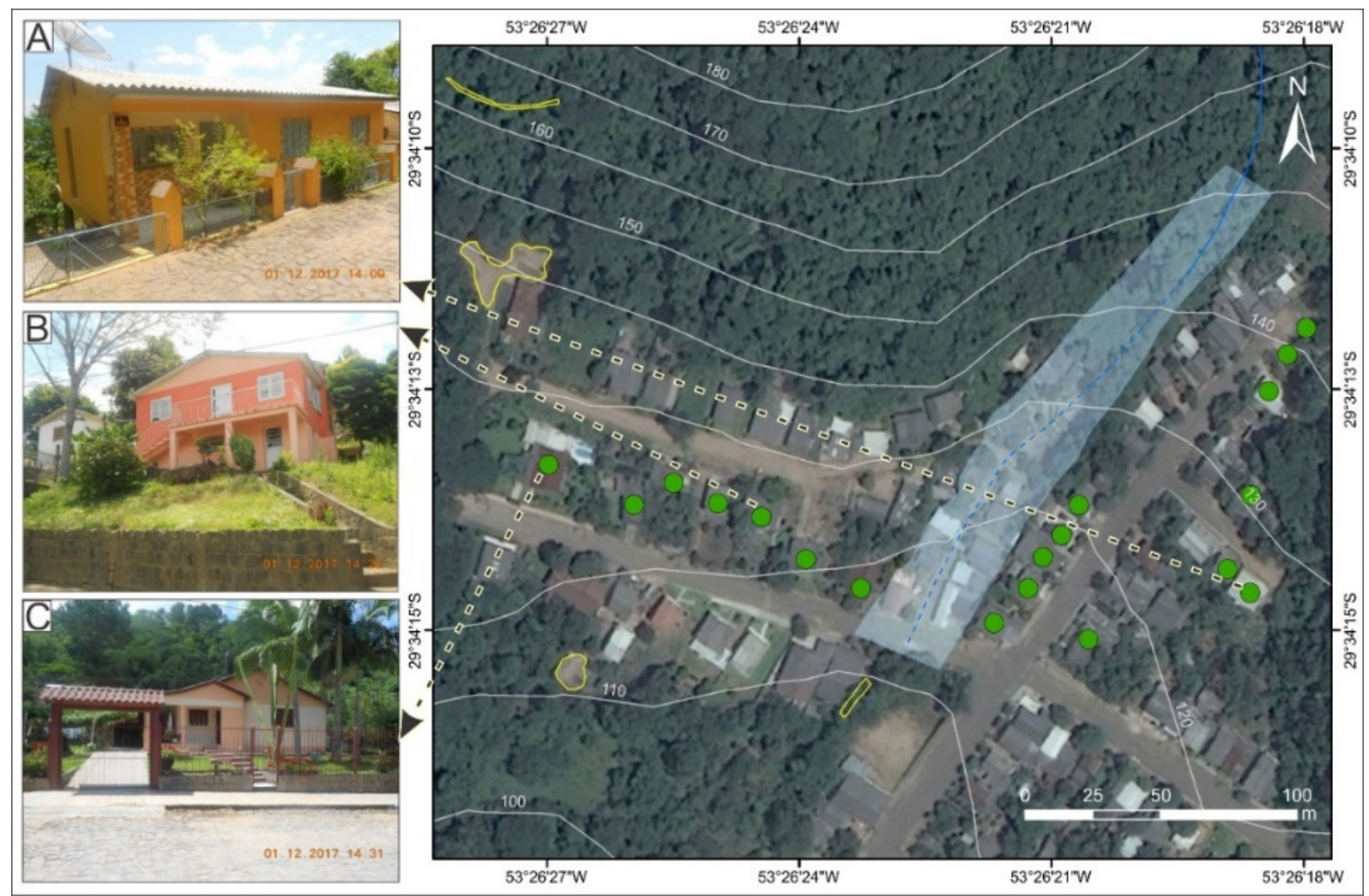

Fonte: Organização dos autores.

As áreas de perigo médio correspondem a 25,71\% das edificações cadastradas (Figura 5), apresentam os condicionantes naturais predisponentes e 0 nível de intervenção antrópica com potencialidade média para o desenvolvimento de processos que ocasionam danos e, por conseguinte, para ocorrência de um 
desastre natural. Nesse sentido, observa-se a presença de indícios de potencialidade e/ou instabilidade de encostas em estágio inicial de desenvolvimento, como também de (re)ocorrência de enxurradas, entretanto incipientes.

A disposição espacial do perigo médio ocorre em locais mais afastados da base da encosta declivosa. A execução de cortes e aterros nos lotes para a construção das edificações caracterizam uma situação de perigo, assim como a (re)ocorrência de enxurradas, porém em locais de menor grau de severidade em relação as classes de perigo alto e muito alto.

Figura 5- Situações de perigo médio na vila Medianeira (A, B e C).



Fonte: Organização dos autores.

As áreas de perigo alto totalizam o cadastro de $25,71 \%$ das edificações (Figura 6), apresentam os condicionantes naturais predisponentes e o nível de intervenção antrópica que podem potencializar o desenvolvimento de processos 
que ocasionam danos. Observa-se a presença significativa de indícios de instabilidade de encostas ou há a (re)incidência de enxurradas.

A disposição espacial dos locais de perigo alto ocorre na base da encosta declivosa e na meia encosta em áreas suscetíveis a enxurradas decorrentes do extravasamento fluvial de uma cabeceira de drenagem tributária do rio Soturno que foi canalizada. Em áreas próximas ao vale fluvial são suscetíveis processos de escorregamento rotacional, como também a disposição de árvores de grande porte isoladas que se tornam em outro fator de perigo em função da proximidade das mesmas as edificações e suas consequências como efeito alavanca, tombamento ou queda de galhos.

Quanto as ações antrópicas, observa-se o descarte de lixo e inserção de espécies vegetais como de bananeiras que podem atribuir peso aos taludes, como também o lançamento de águas servidas que agregam maior umidade de maneira constante a esses locais. Ademais, a execução de cortes e aterros para o nivelamento dos lotes, assim como, a construção das edificações próximo aos locais de perigo como de vale, encosta declivosa e de cortes de talude.

Figura 6- Situações de perigo alto na vila Medianeira (A, B e C). 


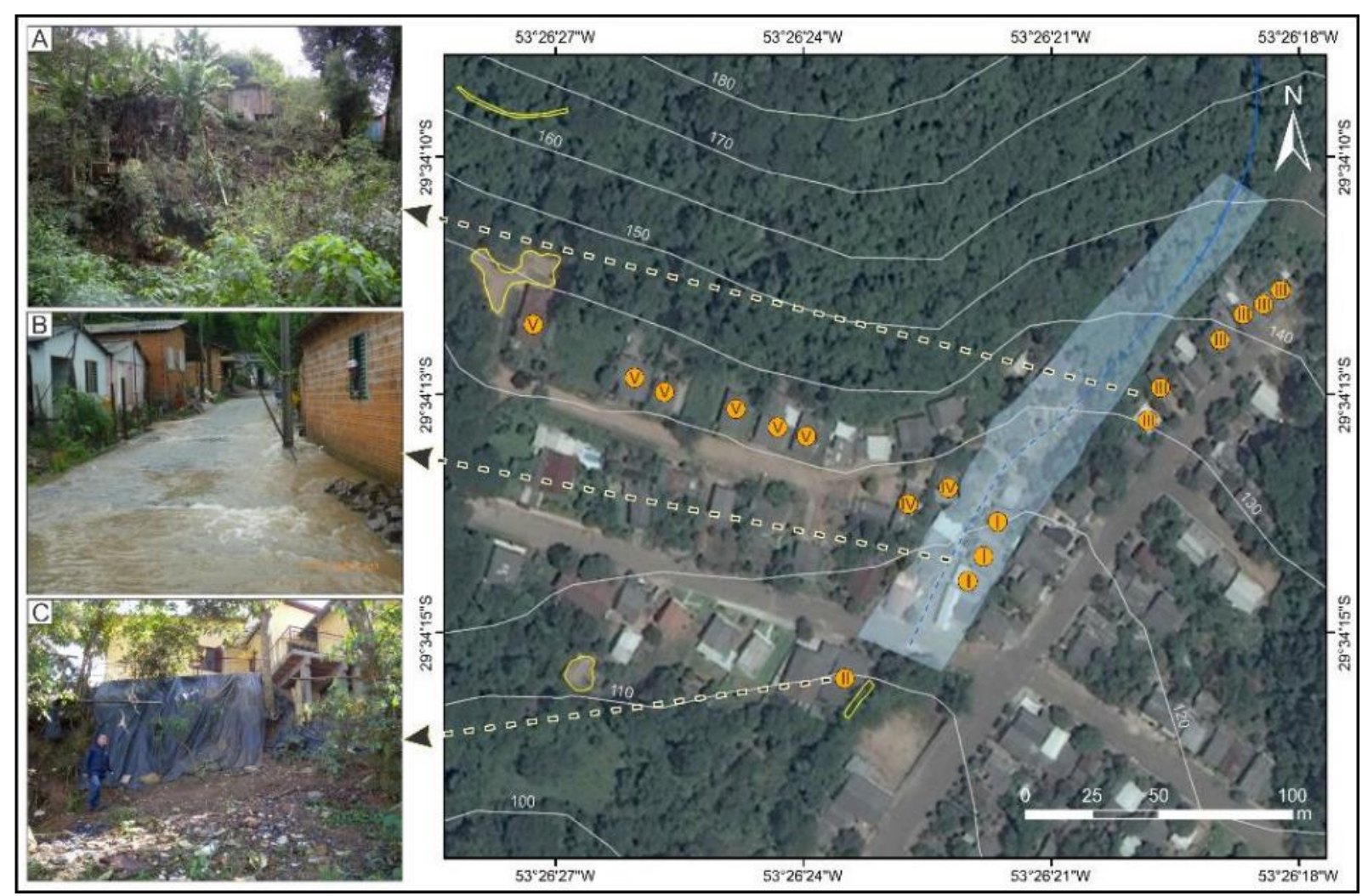

Fonte: Organização dos autores (fotografia B disponibilizada pela Defesa Civil Municipal de Faxinal do Soturno).

No grau de perigo alto foram setorizadas cinco áreas de perigo, que convergem as edificações cadastradas similaridade em relação as condições de danos potenciais:

I) Como primeira situação de perigo alto destaca-se uma área suscetível a processos de dinâmica fluvial do tipo enxurrada que afeta três edificações. Os processos são recorrentes mediante precipitação intensa e concentrada ou acumulada. Caracteriza-se por ser uma rua calçada em local jusante a uma cabeceira de drenagem que foi canalizada. Dessa forma, mediante o aumento da vazão fluvial em eventos de precipitação associado ao sistema de drenagem pluvial ineficiente, resulta no processo que ocasiona danos.

II) A segunda situação de perigo alto corresponde a uma área de corte e aterro na qual localiza-se uma residência e ponto comercial. Identifica-se a edificação sobre um talude com aproximadamente $3 \mathrm{~m}$ de amplitude, em que foram realizadas intervenções estruturais e impermeabilização do local em razão 
dos processos de instabilização. Na base desse talude observou-se depósitos de tálus e colúvio, raízes expostas e indícios de concentração de água oriunda dos excedentes pluviais da rua perpendicular a edificação a qual é afetada por processos de enxurrada.

III) A terceira situação de perigo alto corresponde a seis edificações localizadas próximas ao vale fluvial, em setor de declividade mais acentuada. A ação antrópica atua, por meio do descarte e/ou lançamento de dejetos e águas servidas na encosta e no curso d'água, retirada da cobertura vegetal, como também a inserção de espécies vegetais (bananeiras) que atribuem peso ao talude. Nesse sentido, a área é suscetível a processos de escorregamento, queda ou tombamento de árvores de grande porte isoladas ou de galhos que podem atingir as edificações. Observou-se cortes e aterros laterais e ao fundo dos lotes, os quais podem variar de pequena amplitude até medidas superiores a amplitude da parede das edificações próximos as mesmas.

IV) A quarta situação de perigo alto identificada na área de estudo remete a duas edificações localizadas em área de cortes e aterros laterais e ao fundo dos lotes, próximos as edificações. Observou-se indícios de feições erosivas e blocos de rochas, como tálus e colúvio, além de descarte de dejetos e/ou lixo na área de corte, o que potencializa processos de escorregamento rotacional do material de aterro e descarte.

V) A quinta situação de perigo alto atribui-se a condição de seis edificações localizadas na base da encosta declivosa (morro). No local as edificações encontram-se próximas a encosta, que apresenta grande amplitude altimétrica (superior a $100 \mathrm{~m}$ ), foram realizados cortes e aterros para o nivelamento dos lotes e construção das edificações, como também a retirada da cobertura vegetal. Nesse sentido, constatou-se árvores de grande porte isoladas e presença de blocos rochosos de diferentes dimensões oriundos de porções superiores da encosta, feições erosivas, como também uma situação na qual ocorreu processo de escorregamento próximo a uma edificação. 
As áreas de perigo muito alto correspondem a $21,43 \%$ das edificações cadastradas (Figura 7), e caracterizam-se em apresentar os condicionantes naturais predisponentes e o nível de intervenção antrópica com potencialidade muito alta para o desenvolvimento de processos que ocasionam danos e, por conseguinte, desencadear um desastre natural.

Dessa forma, observam-se indícios de instabilidade de encostas como trincas no solo, em edificações ou em muros, árvores inclinadas, cicatrizes de escorregamentos, feições erosivas, presença de blocos de rochas, entre outros. Os respectivos indícios são expressivos nos locais de perigo muito alto e estão presentes em grande número, ou ainda existem, em algumas situações a (re)ocorrência de enxurradas com maior magnitude. Assim sendo, os processos de instabilização de encostas apresentam-se em avançado estágio de desenvolvimento e/ou as enxurradas caracterizam-se como processos recorrentes, além disso, os respectivos processos causadores de danos podem atuar de maneira simultânea.

Para o grau de perigo muito alto foram identificadas quatro situações de perigo, que atribuem as edificações cadastradas semelhança em relação as condições de danos potenciais:

I) Como primeira situação de perigo muito alto destaca-se uma edificação localizada próxima ao vale fluvial canalizado ao fundo de um lote. A condição de perigo remete a um corte lateral e atrás da edificação, próximos a mesma, além da presença de árvores de grande porte isoladas, presença de raízes expostas e o descarte de lixo e/ou dejetos. Em razão disso, a área torna-se suscetível a processos de escorregamento tanto na lateral quanto ao fundo do lote, como também a queda e/ou tombamento de árvores e galhos.

II) A segunda situação de perigo muito alto corresponde a uma área em que ocorreu processo de escorregamento rotacional associado a depósitos e descarte de lixo em local inadequado agregado ao lançamento de águas servidas. A área em 
que ocorreu o processo, localiza-se próxima a edificação, aproximadamente $2 \mathrm{~m}$, e apresenta trincas no terreno. No local ainda persistem ações de descarte de lixo e lançamento de águas servidas, as quais atribuem umidade e peso ao talude e potencializam novos eventos como o já ocorrido. Nesse sentido, ações como a limpeza da área, o não lançamento de águas servidas, não descarte de dejetos e/ou lixo e a impermeabilização do local são ações que podem atenuar novos processos que ocasionem danos.

Figura 7- Situações de perigo muito alto na vila Medianeira (A, B e C).

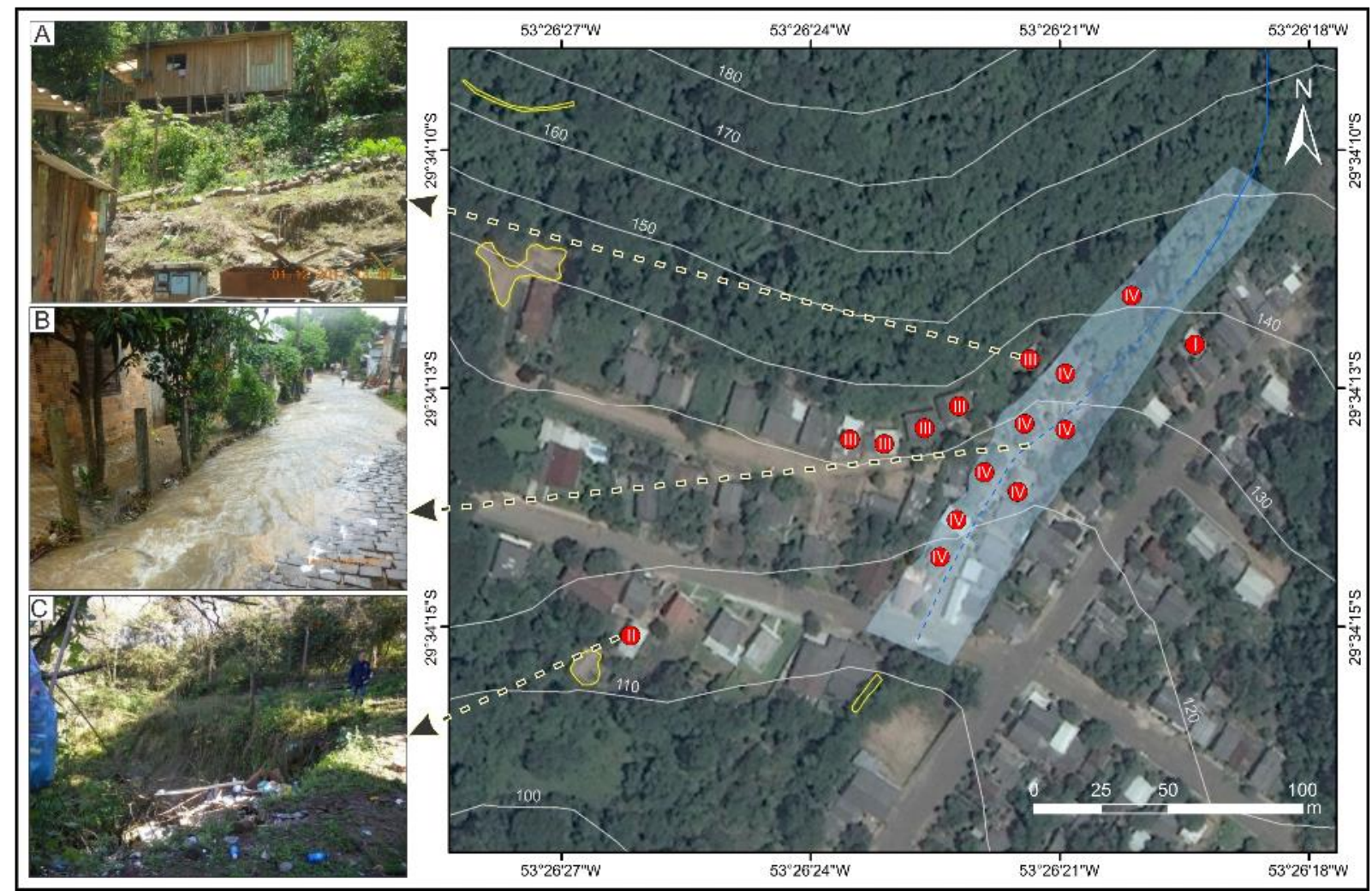

Fonte: Organização dos autores (fotografia B disponibilizada pela Defesa Civil Municipal de Faxinal do Soturno).

III) A terceira situação de perigo muito alto corresponde a cinco edificações localizadas na base da encosta declivosa (morro) e próximas a árvores de grande porte isoladas. A área é suscetível a processos de escorregamento, rolamento de blocos e ao tombamento ou queda de árvores e de galhos. No local observaramse ações antrópicas como cortes e aterros para construção das edificações ao fundo e nas laterais dos lotes, como também a retirada da cobertura vegetal, com 
presença de árvores de grande porte isoladas e inserção de espécies exóticas como bananeiras que atribuem peso aos taludes. Foram identificadas edificações com rachaduras, associado a um possível processo de rastejo e, em um dos casos foi necessária a desocupação da edificação. Ademais, observou-se a presença de blocos de rocha de diferentes dimensões de segmentos superiores da encosta e mediante eventos de precipitação intensa, concentrada e/ou acumulada ocorrem processos de escoamento de água pluvial oriundo da encosta.

IV) A quarta situação de perigo muito alto na área de estudo, corresponde ao conjunto de oito edificações situadas em local de recorrência de enxurradas. $\mathrm{O}$ setor também se torna suscetível a processos do tipo corridas de lama e detritos em razão de caracterizar uma área de convergência de um vale fluvial. Observaram-se ações antrópicas de cortes laterais e ao fundo de alguns dos lotes, muito próximos às edificações, em alguns casos, com dimensões de aproximadamente $2,5 \mathrm{~m}$ de amplitude que tornam a área suscetível a processos de escorregamento, além da identificação de indícios de solapamento do terreno e feições erosivas na base das edificações.

O perigo para que ocorram processos que ocasionem danos na vila Medianeira, acontece, em função, da área ser naturalmente suscetível as ameaças (movimentos de massa e enxurradas) e o fator antrópico atribui a área situações de perigo, seja devido apenas ao processo de ocupar esses espaços ou pelas intervenções desempenhadas de maneira localizada pelos sujeitos que potencializam ou acentuam as condições de perigo.

\section{CONSIDERAÇÕES FINAIS}

A área de estudo apresenta características naturais que a identificam como suscetível aos processos de dinâmica superficial, e em função da ocupação e das intervenções antrópicas atribuem ao local a condição de perigo. A metodologia 
apresentada para mensuração das variáveis foi julgada satisfatória, pois possibilitou identificar situações de perigo na área de estudo. Para a escolha dos itens de análise foram consideradas informações disponíveis na literatura.

A partir disso, desenvolveu-se uma ficha cadastral que agregou pesos e notas para as situações de perigo que foi estruturado com quatro graus de severidade, entre baixo, médio, alto e muito alto. Desse modo, expressaram por meio de uma cartografia quantitativa os locais que demandam de atenção e situações em que os sujeitos possuem condições de conviver com o perigo potencial.

A utilização de técnicas de geoprocessamento tornou possível o mapeamento e cadastro da área de estudo, com representações cartográficas adequadas as informações validadas durante os trabalhos de campo. O banco de dados cartográfico, possibilita atualizações o que visam contribuir para o gerenciamento de risco dessas áreas.

A pesquisa possibilitou o mapeamento e cadastro de 70 edificações em áreas de perigos aos movimentos de massa e enxurradas. As edificações puderam ser identificadas, respectivamente em $27,15 \%$ com perigo baixo, 25,71\% com perigo médio, $25,71 \%$ com perigo alto e $21,43 \%$ com perigo muito alto. As classes de perigo alto e muito alto, ainda puderam ser setorizadas de acordo com a semelhança em relação as condições de danos potenciais e processos de risco atuantes. Nesse sentido, foram identificadas situações de perigo decorrentes de instabilidades em encostas como trincas no solo, trincas em moradias ou em muros, cicatrizes de escorregamentos, presença de blocos de rochas, feições erosivas, árvores de grande porte isoladas e a recorrência de enxurradas.

O presente estudo do perigo serve como uma ferramenta para gestão e gerenciamento de risco de desastres naturais no município de Faxinal do Soturno, à medida em que retrata diferentes situações de perigo e setoriza elementos que potencializam danos nos locais analisados. Desse modo, possibilita aos agentes empenhados no planejamento e ordenamento do espaço urbano, como também 
a Defesa Civil municipal ações nas áreas que demandam maior atenção e, por conseguinte, mitigação para o perigo.

Por fim, sugere-se que sejam realizados estudos prévios para a ocupação de novas áreas no local, em razão da sua suscetibilidade aos processos que ocasionam danos como movimentos de massa e enxurradas. Como também, que seja realizada a análise da vulnerabilidade social e do risco de desastres naturais.

\section{AGRADECIMENTOS}

A Coordenação de Aperfeiçoamento de Pessoal de Nível Superior (CAPES), ao Conselho Nacional de Desenvolvimento Científico e Tecnológico (CNPq) e a Defesa Civil municipal de Faxinal do Soturno - RS.

\section{REFERÊNCIAS}

ALHEIROS, M. M. Riscos de escorregamentos na região metropolitana do Recife. 1998. 135p. Tese (Doutorado em Ciências Geologia). Universidade Federal da Bahia, Salvador.

AMARAL, C.; FEIJÓ, R. L. Aspectos ambientais dos escorregamentos em áreas urbanas. In: VITTE, A. C.; GUERRA, A. J. T. (Orgs.). Reflexões sobre geografia física no Brasil. 7.ed Rio de Janeiro: Editora Bertrand Brasil, 2014. p. 193-223.

AUGUSTO FILHO, O.; VIRGILI, J. C. Estabilidade de taludes. In: OLIVEIRA, A. M. S.; BRITO, S. N. A. (Orgs.). Geologia de engenharia. São Paulo: Associação Brasileira de Geologia de Engenharia, 1998. p. 243-269.

AVILA, L.O. Vulnerabilidade das áreas sob ameaça de desastres naturais na cidade de Santa Maria/RS. 2015. 250p. Tese (Doutorado em Geografia). Universidade Federal do Rio Grande do Sul, Porto Alegre.

BANDEIRA, A. P. Mapa de risco de erosão e escorregamento das encostas com ocupações desordenadas no município de Camaragibe-PE. 2003. 209p. Dissertação (Mestrado em Engenharia Civil). Universidade Federal de Pernambuco, Recife.

BIGARELLA, J. J. Estrutura e origem das paisagens tropicais e subtropicais. Florianópolis: Editora da UFSC, vol. 3, 2003. 
BRASIL. Ministério das Cidades / Instituto de Pesquisas Tecnológicas - IPT. CARVALHO, C.S.; MACEDO, E.S.; OGURA, A.T. (Orgs.). Mapeamento de Riscos em Encostas e Margem de Rios. Brasília: Ministério das Cidades; Instituto de Pesquisas Tecnológicas - IPT, 2007.

CASTRO, A. L. C. Glossário de Defesa Civil: Estudos de riscos e medicina de desastres. 2.ed. Revista e Ampliada. Brasília: Ministério do Planejamento e Orçamento - Secretaria Especial de Políticas Regionais - Departamento de Defesa Civil, 1998.

CERRI, L. E. S.; AMARAL, C. P. Riscos geológicos. In: OLIVEIRA, A. M. S.; BRITO, S. N. A. (Orgs.). Geologia de engenharia. São Paulo: Associação Brasileira de Geologia de Engenharia, 1998. p. 301-310.

CERRI, L. E. S.; NOGUeIRA, F. R.; CARVAlHO, C. S.; MACEDO, E. S.; AUGUSTO FILHO, O. Mapeamento de risco em assentamentos precários no município de São Paulo (SP). São Paulo, UNESP, Geociências, São Paulo, vol. 26, n. 2, p. 143-150, 2007.

CPRM. Serviço Geológico do Brasil. Mapa Geológico do Rio Grande do Sul. Escala 1:750.000, 2006. Disponível em: < http://www.cprm.gov.br/>. Acesso em 18 jan. 2017.

DEFESA CIVIL DO ESTADO DO RIO GRANDE DO SUL. Faxinal do Soturno. Porto Alegre/RS: Coordenadoria Estadual de Defesa Civil. Disponível em: $<$ http://www2.defesacivil.rs.gov.br/SGDC/MConvenios/ConvInterMuniNew.asp?msg=\&iddecre to=\&idopm=0\&idmunicipio=165\&idtpevento=0\&dtinicial=01/01/2011\&dtfinal=27/12/2017\&idt psolicitacao=\&nopred=\&popatingida=>. Acesso em 18 jul. 2017.

DEFESA CIVIL MUNICIPAL DE FAXINAL DO SOTURNO. Acervo Fotográfico. Faxinal do Soturno/RS: Secretaria da Agricultura e Departamento do Meio Ambiente, Prefeitura Municipal de Faxinal do Soturno. Disponível em: $<$ http://www.faxinaldosoturno.rs.gov.br/secretarias/secretaria-da-agricultura-edepartamento-do-meio-ambiente>. Acesso em 18 jul. 2017.

FARIA, D. G. M. Mapeamento de perigo de escorregamentos em áreas urbanas precárias brasileiras com a incorporação do processo de análise hierárquica (AHP). 2011. 194p. vol. 1.Tese (Doutorado em Ciências). Universidade de São Paulo, São Carlos.

FERNANDES, N. F.; AMARAL, C. P. Movimentos de massa: uma abordagem geológicogeomorfológica. In: GUERRA, A. J. T.; CUNHA, S. B (Orgs.). Geomorfologia e meio ambiente. 11.ed. Rio de Janeiro: Editora Bertrand Brasil, 2012. 123-194.

GOOGLE EARTH PRO. Interface do usuário. 2017. Disponível em: < https://www.google.com.br/intl/pt-BR/earth/>. Acesso em 01 nov. 2018.

GUIDICINI, G.; NIEBLE, C. M. Estabilidade de taludes naturais e de escavação. 2.ed. São Paulo: Edgar Blucher Ltda, 1984. 
GUIMARÃES, R. F.; CARVALHO JÚNIOR, O. A.; GOMES, R. A. T.; FERNANDES, N. F. Movimentos de massa. In: FLORENZANO, T. G. (Org.). Geomorfologia: conceitos e tecnologias atuais. São Paulo: Editora Oficina de Textos, 2008. p. 159-184.

HENRIQUE, H. M. Mapa de risco a deslizamento e erosão do bairro de Rurópolis, município do Ipojuca-PE. 2014. 160p. Dissertação (Mestrado em Engenharia Civil). Universidade Federal de Pernambuco, Recife.

INSTITUTO BRASILEIRO DE GEOGRAFIA E ESTATÍSTICA (IBGE). Base Cartográfica Municipal. Escala $1: \quad 50.000, \quad 2010$ Disponível em: ftp://geoftp.ibge.gov.br/organizacao_do_territorio/malhas_territoriais/malhas_municipais/mu nicipio_2015/UFs/RS/>. Acesso em 09 ago. 2018.

INSTITUTO DE PESQUISAS TECNOLÓGICAS (IPT). Mapeamento Geomorfológico do Estado de São Paulo. São Paulo. Escala 1:500.000, vol. 2. p. 130, 1981.

KORMANN, T. C. Ocupação de encostas no município de Blumenau - SC: estudo da formação das áreas de risco a movimentos de massa. 2014. 146p. Dissertação (Mestrado em Geografia). Universidade Federal do Rio Grande do Sul, Porto Alegre.

LISTO, F. L. R.; VIEIRA, B. C. Mapping of risk and susceptibility of shallow-landslide in the city of São Paulo, Brazil. Geomorphology, vol. 169-170, n. 1, p. 30-44, out. 2012.

MAIA, L. P. Geomorfologia Aplicada: Teoria e Prática. Mercator - Revista da Geografia da UFC, Fortaleza, vol. 1, n. 2, p. 133-137, jan. 2002.

MENEZES, D. J. Zoneamento das áreas de risco de inundação na área urbana de Santa Cruz do Sul - RS. 2014. 137p. Dissertação (Mestrado em Geografia). Universidade Federal de Santa Maria, Santa Maria.

NOGUEIRA, F. R. Gestão dos Riscos nos Municípios. In: CARVALHO, C. S.; GALVÃO, T. (Orgs.). Prevenção de Riscos de Deslizamentos em Encostas: Guia para Elaboração de Políticas Municipais. Brasília: Ministério das Cidades; Cities Alliance, 2006.

NUMMER, A. V.; PINHEIRO, R. J. B. Dinâmica de Encosta: movimentos de massa. In: ROBAINA, L. E. S.; TRENTIN, R. (Orgs.). Desastres Naturais no Rio Grande do Sul. Santa Maria: Editora da UFSM, 2013. p. 67-96.

NUNES, L. H. Urbanização e desastres naturais: abrangência na América do Sul. São Paulo: Oficina de Textos, 2015.

PAMPLONA, J.; VALENTE, T. Avaliação do risco à ocorrência de movimentos de massa: proposta de uma metodologia. Comunicações Geológicas, vol. 101, Especial II, p. 923-926. 2014. 
RODRIGUES, F. S.; LISTO, F. L. R. Mapeamento de áreas de risco a escorregamentos e inundações em áreas marginais a rodovias na Região Metropolitana de São Paulo. Engenharia Sanitária e Ambiental, vol. 21, n. 4, p. 765-775, out/dez. 2016.

SCHIRMER, G. J. Mapeamento geoambiental dos municípios de Agudo, Dona Francisca, Faxinal do Soturno, Nova Palma e Pinhal Grande - RS. 2012. 155p. Dissertação (Mestrado em Geografia) - Universidade Federal de Santa Maria, Santa Maria.

TOMINAGA, L. K. Análise e mapeamento de risco In: TOMINAGA, L. K.; SANTORO, J.; AMARAL, R. (Orgs.). Desastres naturais: conhecer para prevenir. 3.ed. São Paulo: Instituto Geológico, 2015a. p. 147-160.

TOMINAGA, L. K. Desastres naturais: por que ocorrem? In: TOMINAGA, L. K.; SANTORO, J.; AMARAL, R. (Orgs.). Desastres naturais: conhecer para prevenir. 3.ed. São Paulo: Instituto Geológico, 2015b. p. 11-23.

TOMINAGA, L. K. Escorregamentos. In: TOMINAGA, L. K.; SANTORO, J.; AMARAL, R. (Orgs.). Desastres naturais: conhecer para prevenir. 3.ed. São Paulo: Instituto Geológico, 2015c, p. 25-38.

TOMINAGA, L. K. Avaliação de metodologias de análise de risco a escorregamentos: aplicação de um ensaio em Umbatuba, SP. 2007. 220p. Tese (Doutorado em Ciências Geografia Física). Universidade de São Paulo, São Paulo.

UNISDR - INTERNATIONAL STRATEGY FOR DISASTER REDUCTION, 2009. Terminology on Disaster Risk Reduction. Disponível em: <www.unisdr.org>. Acesso em 20 fev. 2018.

WIGGERS, M. M. Zoneamento das áreas de risco a movimentos de massa no perímetro urbano do município de Caxias do Sul (RS). 2013. 131 p. Dissertação (Mestrado em Geografia). Universidade Federal do Rio Grande do Sul, Porto Alegre.

\section{1 - Nome completo autor/a:}

Titulação,

link do Orcid e e-mail:

Contribuição:

\section{2 - Nome completo autor/a:}

Vínculo institucional, titulação

link do Orcid e e-mail:

Contribuição:

\section{3 - Exemplo de nome}

Engenheiro Ambiental, Doutor em Engenharia Ambiental

https://orcid.org/0000-0000-0000-0000• exemplodeemail@ufsm.com

Contribuição: Escrita - Primeira Redação 


\section{Como citar este artigo}

AUTORIA. Título do artigo. Geografia Ensino \& Pesquisa, Santa Maria, v. xx, exx, p. xx-xx, 2021. DOI 10.5902/22364994xxxxx. Disponível em: https://doi.org/10.5902/22364994xxxxx. Acesso em: dia mês abreviado. ano. 